\title{
Sacred recipes: The praxis, power, and politics of Black food culture
}

\author{
Lauren W. Forbes * \\ Georgia State University
}

Review of Black Food Matters: Racial Justice in the Wake of Food Justice, edited by Hanna Garth and Ashanté M. Reese. (2020). University of Minnesota Press. Available as Kindle, hardcover, paperback, and audiobook; 308 pages. Publisher's website: https://www.upress.umn.edu/book-division/books/blackfood-matters

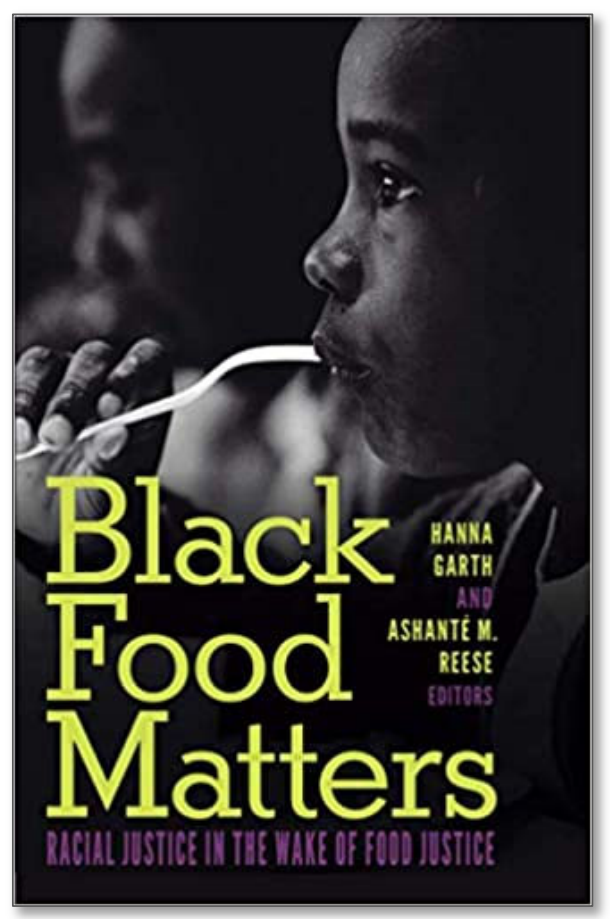

Submitted January 25, 2021 / Published online March 24, 2021

Citation: Forbes, L. W. (2021). Sacred recipes: The praxis, power, and politics of Black food culture [Book review]. Journal of Agriculture, Food Systems, and Community Development, 10(2), 591-594. https://doi.org/10.5304/jafscd.2021.102.045

Copyright (C) 2021 by the Author. Published by the Lyson Center for Civic Agriculture and Food Systems. Open access under CC-BY license.

\section{G} arth and Reese's edited volume Black Food Matters paints a vivid picture of the evolution of Black food culture as it negotiates the sociocultural and political complexities surrounding food and race in America. This work centers around the manifestation of Black food in all its stages, from seed to plate, recognizing that it is both a reflection of the lived experiences of Black people in America and an outright rejection of the harm inflicted on them through a persistently anti-

* Lauren W. Forbes is a Ph.D. candidate at Georgia State University Andrew Young School of Policy Studies, where she specializes in urban policy. Her dissertation research focuses on Black-led urban agriculture, community development, and local food systems. She can be contacted atlforbes5@gsu.edu.
Black structural context. The authors trace the resistance and survival praxis of Black food culture from its earliest origins in the practices of slaves on the Middle Passage to the contemporary practices of local-food-based economies in Black urban and rural communities across the nation. In doing so, each of the authors highlights the ongoing threat that racial capitalism poses to the cultural integrity and socio-economic sustainability of Black communities. Readers are able to draw valuable comparisons between the past and present as they see how Black alimentary and economic autarky have consistently been met with multifaceted exploitation by mainstream, white-dominated society. And yet, the stories told by the book's authors are ones 
of resilience and dignity, highlighting the innovation, adaptability, and fortitude of Black people, as reflected in both African-American and Afrodiasporic food culture.

Setting the book's tone of unapologetic critical inquiry right from the outset (a tone carried, more or less, throughout the book), Garth and Reese highlight the intrinsic ways in which "food justice" is tied to racial justice, suggesting that any efforts to address the former without fundamentally addressing the latter are not only ineffective but often harmful to achieving equity in low-resourced, Black communities. Importantly, they center the widely overlooked notion of Black self-determination in both the shaping of Black spaces and the nature of the food within them-a central theme carried across the book's chapters that starkly contrasts the stereotypical narratives about Black dependency and apathy. The authors mention the inseparability of self from the community, which is consistent with common knowledge of African and indigenous cultural values of communality and family-values that are reflected in Black food practices from cultivation methods to food preparation and consumption practices. From this introductory chapter, another theme emerges that is echoed throughout the book; that is, the simultaneous and wholly paradoxical devaluation and appropriation of "Blackness." I use quotes intentionally here because, at least within the realm of appropriation, it seems to be both the essence of Black identity and the sensationalization of it that are appropriated and capitalized on by neoliberal entrepreneurs and food "visionaries," as are illustrated well in chapters 6 and 7.

In chapter 1, Reese discusses her recent work on food access and food memory among Black residents of Washington, D.C.,'s historically Black communities. She describes the glaring economic disparities of these areas and how the rise of the corporate food regime and subsequent gentrification destroyed local food economies. Reese points to several examples from her research on the resilience of these now divested neighborhoods of concentrated poverty and how visionary local food entrepreneurs are operating small businesses to meet community food needs. Although these businesses are clearly not without their challenges, they help nourish the community while restoring community ties and a sense of belongingness.

Reese also mentions two interesting concepts that she refers to as a "barometer of authenticity" (p. 38) and "(in)visibility" (p. 39). These concepts are a very useful way to articulate the difference between authentic cultural experiences (food and otherwise) from those like the ones Billy Hall (chapter 6) and Judith Williams (chapter 10) describe happening in Florida and other places where local food cultures are being appropriated by and misattributed to the innovation of largely white chefs. The term "(in)visibility" can certainly be linked to cultural appropriation through a sort-of "hiding in plain sight" narrative of excuse for the misattribution of Black food culture. Reese shows that Black people in these neighborhoods are neither waiting for nor expecting the government to provide the economic support that the neighborhood needs, but rather are taking local development into their own hands in the best way that they know how. Although much of the content of this chapter stems from Reese's previously published work, it does not feel like a repeat of the same content but rather a valuable supplement to it.

In chapter 2, Gillian Richards-Greaves takes us on a road trip to a small town in South Carolina. Through small details about her family's history and connection to the land there, she makes the reader feel right at home. She traces the history of the Gullah Geechee community who live in this region and their distinct food culture that has been preserved over generations from the rapacious hands of mainstream American historical actors. On page 56, the author references a beautiful quote by Psyche Williams-Forson on the communicative and multidimensional power of food-a cultural reality that Richards-Greaves demonstrates by amplifying the voices of community members who are active participants as both producers and consumers in the local food economy. The field- and farm-to-table food culture of this hardworking community gives residents not only the physical nourishment they need but also maintains a connection to Black cultural heritage and community relationships. These critical defenses, she seems to 
argue (and I agree), prove important under the constant twin threats of racial capitalism and neoliberal development.

Moreover, in chapters 3 and 4, authors Analena Hassberg and Hanna Garth, respectively, continue in this notion of food as a mechanism of Black self-defense by tracing the "early seeds" (Hassberg, Chapter 3) of modern food justice to its roots in Black liberation in Southern California. Hassberg notes the long history of Black food culture being a means of classification and judgment as well as the myriad abuses of the food system against Black bodies. These abuses are well illustrated through the malnutrition-obesity paradox existing in so-called "food deserts" and the community land loss resulting from externally driven land grabs in low-income neighborhoods. She provides a thorough review and a fresh perspective on the grassroots work of the Black Panther Party's oft-cited Breakfast Program, relating it both to the work of other contemporary food justice organizations and to the fear-induced responses of the federal government. Garth also helps to illustrate the indelible legacy of the Black Panther Party's food justice activism by centering the work of Community Service Unlimited-a Los Angelesbased nonprofit that was initially part of the organization. Even more interesting, though, is the author's self-reflection early in the chapter. She tells an anecdote about an experience she had at a speaking event on healthy food with a local nonprofit and how both her own comments and those of the student participants about their favorite foods were disparaged by the individuals leading the group. Her brief retelling of this story was particularly powerful in demonstrating the subconscious, but nonetheless harmful, effects of antiBlackness in the so-called healthy food movement. She eloquently states, "I wondered how the organization might be utilizing my Blackness to legitimize its work while at the same time policing the way in which I express my Blackness and engage with Black food culture" (p. 109). This reflection, both critical and familiar, is an important reminder that even the most well-intentioned individuals can reinforce racialized ideologies within the food system.

Chapters 5 and 8 cover the food system and grocery store context in Detroit, Michigan. In chapter 5, Newman and Jung discuss what they refer to as the "transactional politics" of mainstream food justice and alternative food movements - that is, the centrist, neoliberal approach whereby food insecurity in the city is seen as market failure and a business opportunity rather than a human rights or "human decency" issue. Interestingly, they discuss the "moral meaning of economic exchange," implicitly suggesting that there is a common standard of human worth which our food systems ought to ascribe. I am not sure it is possible to introduce such a fundamentally metaphysical term as "moral" into the discussion without engaging the disciplines of theology and philosophy in which it originates. One would think that such a basic, taken-for-granted concept as human value ought not to be controversial, but alas, it seems to be so, particularly as it relates to the food system injustices experienced by low-income Black and brown people in America and throughout the Global South. Newman and Jung provide empirical insights from Detroit locals about their perspectives on Whole Foods Market and its dominant presence in the city, ending their chapter with the poignant question, "Can one still participate in the moral economy that has sustained Black communities for generations while adhering to a pure market logic?" (p. 151). More than likely, the answer is no. Monica White's contribution in chapter 8 seems to assent to this conclusion. In it, she illustrates, through the lens of ecofeminism, how Black women growers of the Detroit Black Community Food Security Network use traditional food cultivation in the city to combat the myriad structural inequities that harm the wellbeing of Black communities.

Furthermore, Billy Hall and Kimberly Kasper's chapters on Miami, Florida (chapter 6), and Memphis, Tennessee (chapter 7), respectively, remind us of the value of critical self-reflection and personal stories in research. I found the reflexivity of both authors deeply refreshing, given how so much of academia still subconsciously nurtures positivistic research values and norms that eschew subjectivity. Hall's chapter provides an important reflection on the ways in which Black food culture has been rebranded and repackaged to appeal to an affluent, 
largely white "out-of-towner" clientele. As he points out, this relabeling comes with benefits for some local businesses that are included in this new "racial redevelopment machine" (Wilson, 2018, as cited by Hall, p. 160), and creates burdens for many others that, perhaps intentionally, are excluded from it. The strategy being implemented in historic Overtown, rather than in the chapter itself, bears the unmistakable appearance of top-down, neoliberal development with a faint whiff of minstrelsy. Meanwhile, In Kasper's chapter, I thoroughly enjoyed the "smoke and fire" metaphor that she shares from one of her interviewees. Her chapter gave me a much greater appreciation for and respect of barbecue culture, and she left me convinced that the best barbecue I have ever tasted is mere child's play compared to the handiwork of Memphis's legendary pitmasters.

By the time I reached the final chapters on Black land loss (chapter 9) and the Mango Gang (chapter 10), my head, heart, and belly were already full of warm taste memories. I would have liked to have seen the discussion of the Pigford $v$. Glickman (1999) case discussed in light of current proposed federal legislation like the Justice for Black Farmers Act; however, this was likely not possible given the timing of the bill's release. Otherwise, I am glad this chapter was included because land justice is so fundamental to the aspirations and vocalizations of Black food systems activists across the country. The final chapter provided an experiential immersion into Caribbean food culture. The author discusses interethnic hierarchy within the broader Afro-diasporic community, which is something worth discussing further, perhaps through other disciplinary contexts.

In all, Black Food Matters is an excellent read, illustrating the intersection between Black food studies, urban political economy, and equitable development. I recommend it for any academic or lay scholar interested in these subject areas. Practitioners and community activists may also find it useful in their education and advocacy work.

\section{References}

Guthman, J. (2008). Bringing good food to others: Investigating the subjects of alternative food practice. Cultural Geographies, 15(4), 431-447. https://doi.org/10.1177/1474474008094315

Hall, B. (2020). Soul food gentrification: Food, racial heritage tourism, and the redevelopment of Black space in Miami. In H. Garth \& A. M. Reese, Black food matters: Racial justice in the wake of food justice (pp. 158-180). Minneapolis: University of Minnesota Press. https://doi.org/10.5749/j.ctv182jtk0.9

Pigford v. Glickman, 185 F.R.D. 82 (D.D.C. 1999), affd, 206 F.3d 1212 (D.C. Cir. 2000). 